\title{
Analisis technology contribution coefficient (TCC) di UKM Gazal Makmur
}

\author{
Analysis of technology contribution coefficient (TCC) at Gazal Makmur SMEs
}

Cahyuni Novia ${ }^{1 *}$, Iqnatia Sundus Anisa ${ }^{1}$, Ika Rafidah ${ }^{1}$,

${ }^{1}$ Fakultas Teknik, Universitas Nurul Jadid, Probolinggo, Jawa Timur

*Email Korespondensi: vhie771108@gmail.com

Informasi Artikel:

Dikirim: 03/06/2021; disetujui: 25/07/2021; diterbitkan: 28/09/2021

\begin{abstract}
Technology is an important aspect for the success of an industry. Gazal Makmur UKM is an UKM that processes cassava into chips in Gazal Hamlet, Kotaanyar Village, Kotaanyar District, Probolinggo Regency. This study aims to calculate the value of the technology component contribution coefficient (TCC) and determine the priority of technology component development in Gazal Makmur SMEs. The method used in this study is the technometric method, namely the technology assessment method used to evaluate the contribution of technology components and the pairwise comparison matrix approach. The measured technology components include technoware (production equipment), humanware (human resource capabilities), infoware (information tools), and orgaware (organizational tools). The results of this study indicate that the contribution of the Orgaware component is the highest in Gazal Makmur SMEs (0.578), then humanware (0.467), humanware (0.252), and the smallest is technoware (0.0.244). The TCC value for Gazal Makmur SMEs is 0.418. The results of this calculation show that these SMEs have a TCC value below 0.7 and above 0.3, meaning that it can be concluded that these SMEs are classified as having a semimodern level of technology with a reasonable technology category for the SME scale. Improving the quality of Gazal Makmur cassava chips SMEs starts from the orgaware component then humanware, infoware and finally orgaware.
\end{abstract}

Keywords: Cassava chips, contribution of technology, TCC, pairwise comparison

\begin{abstract}
ABSTRAK
Teknologi merupakan aspek penting bagi keberhasilan suatu industri. UKM Gazal Makmur merupakan UKM yang mengolah singkong menjadi keripik di Dusun Gazal Desa Kotaanyar Kecamatan Kotaanyar Kabupaten Probolinggo. Penelitian ini bertujuan untuk menghitung nilai koefisien kontribusi komponen teknologi (TCC) dan menentukan prioritas pengembangan komponen teknologi di UKM Gazal Makmur. Metode yang digunakan dalam penelitian ini adalah metode teknometrik yaitu metode penilaian teknologi yang digunakan untuk mengevaluasi kontribusi komponen teknologi dan pendekatan pairwise comparison matriks. Komponen teknologi yang diukur meliputi technoware (peralataan produksi), humanware (kemampuan sumberdaya manusia), infoware (perangkat informasi), dan orgaware (perangkat organisasi). Hasil penelitian ini menunjukkan bahwa kontribusi komponen Orgaware merupakan yang tertinggi pada UKM Gazal Makmur (0.578), kemudian humanware (0.467), humanware (0.252), dan yang terkecil technoware (0. 0.244). Nilai TCC untuk UKM Gazal Makmur ialah 0.418. Hasil perhitungan ini menunjukkan bahwa UKM ini memiliki nilai TCC dibawah 0,7 dan diatas 0,3 , berarti dapat disimpulkan bahwa UKM ini yang berada di tergolong memiliki level teknologi yang semi modern dengan kategori teknologi
\end{abstract}


wajar untuk skala UKM. Peningkatan mutu UKM keripik singkong Gazal Makmur dimulai dari komponen orgaware kemudian humanware, infoware dan terakhir orgaware.

Kata kunci: Keripik singkong, kontribusi teknologi, TCC, pairwise comparison

\section{PENDAHULUAN}

Usaha Kecil Menengah (UKM) berperan penting dalam pertumbuhan dan stabilisasi perekonomian Indonesia (Novia et al., 2021). Keberadaan Usaha Kecil Menengah (UKM) di suatu daerah dapat meningkatkan kesejahteraan penduduknya lebih cepat dibanding dengan sektor lainnya (Antesty dan Tontowi, 2020). Tetapi produktivitas UKM Indonesia masih dianggap rendah berdasarkan rantai perdagangan di Kawasan Asia Tenggara, di mana sektor UKM hanya memiliki kontribusi sebesar 6,3\% (Kementerian Koperasi dan Kecil dan Menengah Republik Indonesia, 2019). Hal ini disebabkan karena pengembangan UKM masih fokus terhadap pada permodalan / pendanaan dan masalah pemasaran (Antesty et al., 2020). Selain aspek permodalan dan pemasaran, penerapan teknologi dalam UKM merupakan salah satu unsur penting dalam usaha meningkatkan kinerja UKM. Kemampuan suatu industri dalam mengadopsi teknologi memberikan dampak yang sangat signifikan di dalam persaingan industri sejenis (Susihono, 2013).

Industri pengolahan pertanian merupakan salah satu sektor UKM yang dianggap cukup menjanjikan dan sebagai sektor yang membutuhkan penyerapan teknologi pada setiap prosesnya (Purnomo dan Hadi, 2017). Komoditas hasil pertanian yang paling banyak diolah di wilayah Jawa Timur karena ketersediaan bahan baku melimpah adalah singkong. Pada tahun 2017 produksi singkong di Kabupaten Probolinggo sebesar 52.701,00 Ton (BPS Kabupaten Probolinggo, 2020). UKM Gazal Makmur merupakan UKM yang mengolah singkong menjadi keripik di Dusun Gazal Desa Kotaanyar Kecamatan Kotaanyar Kabupaten Probolinggo. Desa Kotaanyar Probolinggo. UKM Gazal makmur saat ini masih menggunakan teknologi yang sederhana dalam memproduksi dan memasarkan keripik singkong yang dihasilkankan. Guna menunjang kebutuhan konsumen akan keripik singkong yang semakin meningkat dan persaingan yang semakin ketat, UKM Gazal Makmur terus berusaha agar tetap bisa mempertahankan pangsa pasar dengan meningkatkan kualitas dan kuantitas produksi. Salah satu cara untuk bertahan dan meningkatkan kualitas mutu keripik singkong ini ialah dengan menciptakan manajemen teknologi yang baik. Perkembangan teknologi lebih cepat dan kompleks dari waktu ke waktu. Oleh karena itu perlu dilakukanya penguatan teknologi dengan cara melakukan analisis manajemen teknologi pada UKM ini agar dapat menjaga kualitas produk dan dapat bersaing dengan pesaingnya. Penelitian ini bertujuan mengetahui nilai Technology Contribution Coefficient (TCC) yang merupakan hasil akhir dari metode teknometrik.

\section{METODE}

Pengambilan data dan pengamatan dilakukan pada bulan April 2021 di UKM Gazal Makmur Probolinggo. Metode pengumpulan data menggunakan metode survei. Data yang digunakan yaitu data primer yang diperoleh melalui wawancara mengenai komponen teknologi technoware, orgaware, humanware, dan inforware. Pengolahan data dilakukan dengan melakukan tabulasi data hasil wawancara.

Penilaian tingkat teknologi UKM keripik singkong Gazal Makmur Probolinggo menggunakan model teknometrik (UNESCAP 1989). Kriteria komponen teknologi yang diteliti mengacu pada kriteria yang digunakan oleh (Utomo \& Setiastuti, 2019). Model teknometrik mendefinisikan koefisien kontribusi teknologi (technology contribution coefficient) dalam suatu fasilitas transformasi. Menurut UN-ESCAP (1989) 
terdapat lima langkah untuk dimulai dari penilaian derajat kecanggihan mengestimasikan nilai TCC, yaitu: komponen teknologi. Setiap komponen

\section{Estimasi derajat kecanggihan}

Berdasarkan hasil observasi lapangan dan wawancara, dilakukan pengolahan data teknologi mendapatkan nilai tepi bawah dan tepi atas. Penentuan nilai tepi bawah dan tepi atas disajikan pada Tabel 1.

Tabel 1. Derajat kecanggihan teknologi

\begin{tabular}{|c|c|c|c|c|}
\hline Technoware & Humanware & Infoware & Orgaware & Skor \\
\hline $\begin{array}{l}\text { Peralatan produksi } \\
\text { manual }\end{array}$ & $\begin{array}{l}\text { Menjalankan } \\
\text { peralatan } \\
\text { produksi }\end{array}$ & $\begin{array}{l}\text { Informasi yang } \\
\text { memberikan } \\
\text { pemahaman umum } \\
\text { dalam menggunakan } \\
\text { peralatan produksi } \\
\end{array}$ & $\begin{array}{l}\text { Perusahaan kecil yang } \\
\text { dipimpin sendiri, modal } \\
\text { kecil, tenaga kerja } \\
\text { sedikit dan pangsa pasar } \\
\text { kecil }\end{array}$ & $1-2-3$ \\
\hline $\begin{array}{l}\text { Peralatan produksi } \\
\text { mekanik atau } \\
\text { elektrik }\end{array}$ & $\begin{array}{l}\text { Memasang } \\
\text { peralatan } \\
\text { produksi }\end{array}$ & $\begin{array}{l}\text { Informasi yang } \\
\text { memberikan } \\
\text { pemahaman teknis } \\
\text { dalam menggunakan } \\
\text { dan memperagakan } \\
\text { peralatan produksi }\end{array}$ & $\begin{array}{l}\text { Perusahaan kecil yang } \\
\text { telah mampu } \\
\text { meningkatkan } \\
\text { kemampuan dan } \\
\text { menjalin Kerjasama } \\
\text { sebagai sub kontraktor } \\
\text { dari perusahaan besar }\end{array}$ & $2-3-4$ \\
\hline $\begin{array}{l}\text { Peralatan produksi } \\
\text { untuk penggunaan } \\
\text { umum }\end{array}$ & $\begin{array}{l}\text { Merawat } \\
\text { peralatan } \\
\text { produksi }\end{array}$ & $\begin{array}{l}\text { Informasi yang } \\
\text { memungkinkan untuk } \\
\text { memilih peralatan } \\
\text { produksi }\end{array}$ & $\begin{array}{l}\text { Telah memiliki jaringan } \\
\text { kerjasama dengan } \\
\text { perusahaan lain dalam } \\
\text { memasarkan produk }\end{array}$ & $3-4-5$ \\
\hline $\begin{array}{l}\text { Peralatan produksi } \\
\text { untuk penggunaan } \\
\text { khusus }\end{array}$ & $\begin{array}{l}\text { Mengelola } \\
\text { peralatan } \\
\text { produksi }\end{array}$ & $\begin{array}{l}\text { Informasi yang } \\
\text { memungkinkan } \\
\text { penggunaan peralatan } \\
\text { produksi secara } \\
\text { efektif }\end{array}$ & $\begin{array}{l}\text { Telah mempunyai } \\
\text { jaringan kerjasama } \\
\text { dengan perusahaan lain } \\
\text { serta mampu } \\
\text { mengidentifikasi produk }\end{array}$ & $4-5-6$ \\
\hline $\begin{array}{l}\text { Peralatan produksi } \\
\text { otomatis }\end{array}$ & $\begin{array}{l}\text { Memodifikasi } \\
\text { peralatan } \\
\text { produksi }\end{array}$ & $\begin{array}{l}\text { Informasi yang dapat } \\
\text { meningkatkan } \\
\text { pengetahuan } \\
\text { mengenai mendesain } \\
\text { dan mengoperasikan } \\
\text { peralatan produksi }\end{array}$ & $\begin{array}{l}\text { Perusahaan telah } \\
\text { mampu bersaing melalui } \\
\text { peningkatan pangsa } \\
\text { pasar dan kualitas } \\
\text { produk secara } \\
\text { berkelanjutan }\end{array}$ & $5-6-7$ \\
\hline $\begin{array}{l}\text { Peralatan produksi } \\
\text { komputerisasi }\end{array}$ & $\begin{array}{l}\text { Memperbaiki } \\
\text { peralatan } \\
\text { produksi yang } \\
\text { rusak }\end{array}$ & $\begin{array}{l}\text { Informasi yang } \\
\text { memungkinkan } \\
\text { terjadinya perbaikan } \\
\text { peralatan produksi }\end{array}$ & $\begin{array}{l}\text { Perusahaan telah } \\
\text { mampu secara cepat dan } \\
\text { stabil membangun } \\
\text { kesuksesan melalui } \\
\text { perluasan pasar baru dan } \\
\text { selalu mengantisipasi } \\
\text { perkembangan internal } \\
\text { dan eksternal } \\
\text { lingkungan usaha }\end{array}$ & $7-8-9$ \\
\hline $\begin{array}{l}\text { Peralatan produksi } \\
\text { berintegrasi }\end{array}$ & $\begin{array}{l}\text { Melakukan } \\
\text { inovasi } \\
\text { peralatan } \\
\text { produksi }\end{array}$ & $\begin{array}{l}\text { Informasi yang bisa } \\
\text { memberikan } \\
\text { penilaian terhadap } \\
\text { peralatan produksi } \\
\text { untuk tujuan-tujuan } \\
\text { yang spesifik }\end{array}$ & $\begin{array}{l}\text { Perusahaan mampu } \\
\text { menjadi pemimpin } \\
\text { terkemuka dalam } \\
\text { spesialisasi usaha atau } \\
\text { produk tertentu }\end{array}$ & $8-9-10$ \\
\hline
\end{tabular}

(Sumber : Utomo dan Setiastuti, 2019). 


\section{Pengkajian state of the art (SOTA)}

Tahapan selanjutnya yaitu penilaian SOTA setiap kriteria dari masing- masing komponen teknologi. State of the art adalah tingkat kecanggihan dari masing-masing komponen teknologi. Sebelum dilakukan pengkajian rating state of the art, terlebih duhulu dilakukan penilaian terhadap kriteriakriteria pada setiap komponen teknologi. Tingkat kecanggihan (STi, SHj, SI dan SO) dihitung menggunakan Persamaan (1-4) (Ayu, 2018):

$$
\begin{aligned}
& S T=\frac{1}{9}\left[\frac{\sum_{k=1}^{k_{t}} t_{k}}{k_{t}}\right] \\
& S H=\frac{1}{9}\left[\frac{\sum_{i=1}^{i_{h}} h_{i}}{i_{h}}\right] \\
& S I=\frac{1}{9}\left[\frac{\sum_{m=1}^{m_{t}} f_{m}}{m_{t}}\right] \\
& S O=\frac{1}{9}\left[\frac{\sum_{n=1}^{n_{O}} O_{n}}{n_{o}}\right]
\end{aligned}
$$

Keterangan :

$\mathrm{k}=1,2,3, \ldots, \mathrm{kt}$

$\mathrm{k}_{\mathrm{t}}=$ jumlah kriteria komponen technoware

$t_{k}=$ skor kriteria ke-k untuk komponen technoware

$\mathrm{i}=1,2,3, \ldots$, ih

$\mathrm{i}_{\mathrm{h}}=$ jumlah kriteria komponen humanware

$h_{i}=$ skor kriteria ke-i untuk komponen humanware

$\mathrm{m}=1,2,3, \ldots, \mathrm{mt}$

$\mathrm{m}_{\mathrm{t}}=$ jumlah kriteria komponen infoware

$f_{m}=$ skor kriteria ke-m untuk komponen infoware

$\mathrm{n}=1,2,3, \ldots$, no

$\mathrm{n}_{\mathrm{o}}=$ jumlah kriteria komponen orgaware

$o_{n}=$ skor kriteria ke-n untuk komponen orgaware

\section{Penentuan kontribusi komponen}

Penentuan nilai kontribusi setiap komponen dilakukan dengan menggunakan nilai batasan derajat kecanggihan dan rating state of the art. Nilai Kontribusi Komponen Teknologi masing-masing aspek (T, H, I dan O) dihitung menggunakan Persamaan (5-8) (Matin \& Toloui, 2014):

$$
\begin{aligned}
T & =\frac{1}{9}[L T+S T(U T-L T)] . \\
H & =\frac{1}{9}[L H+S H(U H-L H)] \\
I & =\frac{1}{9}[L I+S I(U I-L I)] \ldots . . . \\
O & =\frac{1}{9}[L O+S O(U O-L O)]
\end{aligned}
$$

Keterangan :

LT : lower limit komponen technoware

UT : Upper limit komponen technoware

ST : State of the art komponen technoware

LH : Lower limit komponen humanware

SH : State of the art komponen humanware

$\mathrm{UH}$ : upper limit komponen humanware

LI : lower limit komponen Infoware

UI : upper limit komponen Infoware

SI : State of the art komponen Infoware

LO : lower limit komponen Orgaware

SO : State of the art komponen Orgaware

$\mathrm{UH}$ : Upper limit komponen humanware

Sedangkan batas atas (UT, UH, UI dan UO) dan batas bawah (LT, LH, LI dan LO) ditentukan menggunakan Tabel 1 berdasarkan hasil pengamatan dan wawancara ke pelaku UKM.

\section{Pengkajian intensitas kontribusi komponen}

Penghitungan nilai intensitas kontribusi menggunakan Software Criterium Decision Plus. Nilai hasil perhitungan Intensitas Kontribusi Komponen Teknologi yaitu $\beta$ t, $\beta \mathrm{h}, \quad \beta \mathrm{i}$ dan $\beta \mathrm{o}$ didapatkan menggunakan metode Analytic Hierarchy Process (AHP) dengan penggunaan matriks perbandingan berpasangan (pairwise comparison matrix) diantara masing-masing komponen $\mathrm{T}, \mathrm{H}, \mathrm{I}$, O. Syarat konsistensi dalam pengisian kuesioner ini mutlak diperlukan yang diungkapkan dalam bentuk nilai rasio konsistensi. Nilai rasio konsistensi harus bernilai $\leq 0,1$ dan nilai nilai $\beta \mathrm{t}, \beta \mathrm{h}, \beta \mathrm{i}, \beta \mathrm{o}$ merupakan nilai normalized weight.

\section{Penghitungan TCC}

Nilai $\mathrm{T}, \mathrm{H}, \mathrm{I}, \mathrm{O}$ dan nilai $\beta$-nya digunakan untuk menghitung technology coefficient contribution (TCC) dengan menggunakan persamaan: Data ini selanjutnya digunakan untuk menghitung Koefisien Kontribusi Teknologi menggunakan Persamaan (1). Menghitung 
Koefisien kontribusi Teknologi Tingkat kecanggihan UKM keripik singkong Gazal Makmur secara kelembagaan diungkapkan dalam bentuk koefisien kontribusi teknologi (TCC; Technology Contribution Coefficient) yang merangkum aspek keseluruhan yaitu aspek teknologi $(\mathrm{T})$, sumber daya manusia $(\mathrm{H})$, informasi (I) dan organisasi $(\mathrm{O})$, dan diformulasikan oleh UNESCAP (United Nation Economics and Social Commission for Asia Pacific) (Smith dan Sharif, 2007). seperti dalam Persamaan (9) dengan pengklasifikasian seperti deskripsi dalam tabel 2 dan tingkat teknologi pada tabel 3.

$\mathrm{TCC}=\mathrm{T} \beta \mathrm{t} \times \mathrm{H} \beta \mathrm{h} \times \mathrm{I} \beta \mathrm{i} \times \mathrm{O} \beta \mathrm{o}$

Keterangan :

TCC = technology contribution coefficient

$\mathrm{T}=$ nilai kontribusi komponen technoware

$\mathrm{Bt}=$ nilai intensitas konstribusi komponen

Technoware

$\mathrm{H}$ = nilai konstribusi komponen

Humanware

$\mathrm{Bh}=$ nilai intensitas konstribusi

komponen Humanware

I = nilai konstribusi komponen Infoware

$\mathrm{Bi}=$ nilai intensitas konstribusi komponen Infoware

$\mathrm{O}=$ nilai konstribusi komponen Orgaware

Bo = nilai intensitas kontribusi Orgaware

Tabel 2. Klasifikasi TCC

\begin{tabular}{cc}
\hline Nilai TCC & Klasifikasi \\
\hline $0,0<$ TCC $\leq 0,1$ & sangat rendah \\
$0,1<$ TCC $\leq 0,3$ & rendah \\
$0,3<$ TCC $\leq 0,5$ & wajar \\
$0,5<$ TCC $\leq 0,7$ & baik \\
$0,7<$ TCC $\leq 0,9$ & sangat baik \\
$0,9<$ TCC $\leq 1,0$ & kecanggihan mutakhir
\end{tabular}

Sumber: (Wiraatmaja \& Ma'ruf, 2004)

Tabel 3. Tingkat teknologi

\begin{tabular}{cc}
\hline Nilai TCC & Klasifikasi \\
\hline $0,0<\mathrm{TCC} \leq 0,3$ & tradisional \\
$0,3<\mathrm{TCC} \leq 0,7$ & semi modern \\
$0,7<\mathrm{TCC} \leq 1,0$ & modern \\
\hline
\end{tabular}

Sumber: (Wiraatmaja \& Ma'ruf, 2004)

Setelah mendapatkan nilai TCC maka penerapan teknologi di UKM Gazal Makmur dapat diklasifikasikan. Berdasarkan hasil analis tersebut UKM dapat rekomendasi menentukan strategi perbaikan teknologi sebagai satu strategi untuk dapat bersaing di industri makanan khususnya keripik singkong.

\section{HASIL DAN PEMBAHASAN}

\section{Batas tingkat kecangggihan}

Batas tingkat kecanggihan komponen teknologi dari UKM keripik singkong yang ditunjukkan pada Tabel 4.

Tabel 4 Batas Tingkat Kecanggihan

Komponen Teknologi pada UKM Gazal

Makmur

\begin{tabular}{lcc}
\hline \multirow{2}{*}{ Komponen Teknologi } & \multicolumn{2}{c}{ Tingkat } \\
& \multicolumn{2}{c}{ Kecanggihan } \\
\cline { 2 - 3 } & Ul & Makmur \\
& 1 & 4 \\
\hline Technoware & 2 & 7 \\
Humanware & 1 & 4 \\
Infoware & 5 & 7 \\
Orgaware & 5
\end{tabular}

Sumber : Data primer, diolah (2021)

Estimasi terhadap derajat kecanggihan komponen teknologi yang disajikan pada Tabel 4. Nilai-nilai yang tertera menunjukkan bahwa: 1. Dari komponen technoware: terdapat penggunaan peralatan produksi secara manual (1), dan peralatan produksi mekanik atau elektrik (4); 2. Dari komponen humanware: pegawai mampu menjalankan peralatan produksi (2) dan ada pegawai yang mampu merawat dan memodifikasi peralatan produksi (7); 3. Dari komponen infoware: Informasi yang memberikan pemahaman umum dalam menggunakan peralatan produksi (1) dan ada Informasi yang memberikan pemahaman teknis dalam menggunakan dan memperagakan peralatan produksi (4); 4. Dari komponen orgaware : ada jaringan kerjasama dengan perusahaan lain dalam memasarkan produk (5) dan perusahaan mempunyai spesialisasi produk yaitu pada produk keripik singkong (7).

\section{State of the art (SOTA)}

Hasil penilaian kecanggihan mutakhir (State of the Art/SOTA) technoware 
disajikan pada Tabel 5. Kriteria technoware pada skor 5. Hal ini karena UKM belum di UKM Gazal makmur maksimal hanya memiliki alat-alat produksi yang otomatis.

Tabel 5. Penilaian SOTA komponen technoware

\begin{tabular}{llc}
\hline No & Kriteria Technoware & Skor \\
\hline 1 & Proses Pengupasan Singkong & 2.5 \\
\hline 2 & Proses Pencucian Singkong & 2.5 \\
\hline 3 & Proses Pengirisan Singkong & 5 \\
\hline 4 & Proses Perendaman Singkong & 2.5 \\
\hline 5 & Proses Penjemuran Singkong & 2.5 \\
\hline 6 & Proses Penggorengan Singkong & 5 \\
\hline 7 & Proses penirisan keripik singkong & 5 \\
\hline 8 & Pengemasan keripik singkong & 5 \\
\hline & Total & 30 \\
\hline & Rata-rata & 3.75 \\
\hline & State of the Art & 0.38
\end{tabular}

Sumber : Data primer, diolah (2021)

Tabel 6. Penilaian SOTA komponen humanware

\begin{tabular}{|c|l|c|}
\hline No & \multicolumn{1}{|c|}{ Kriteria Humanware } & Skor \\
\hline 1 & Kemampuan Memelihara Fasilitas Produksi & 5 \\
\hline 2 & Kesadaran Bekerja Dalam Kelompok & 5 \\
\hline 3 & Kemampuan Bekerjasama & 7 \\
\hline 4 & Kreativitas dan Inovasi & 4 \\
\hline 5 & Kedisiplinan dan Tanggung Jawab & 5 \\
\hline 6 & Kemampuan untuk Menyelesikan Masalah & 5 \\
\hline \multicolumn{2}{|c|}{ Total } & 31 \\
\hline Rata-rata & 5.12 \\
\hline State of the Art & 0.52 \\
\hline
\end{tabular}

Sumber : Data primer, diolah (2021)

Hasil penilaian kriteria humanware hanya di point 3 atau kemampuan kerjasama yang dimiliki oleh pekerja dan pemilik yang memiliki skor paling tinggi. Hal ini disebabkan pemilik sangat memperhatikan seluruh pekerjanya dan mereka merasa nyaman dalam bekerja. Hal ini sejalan dengan hasil penelitian (Sanyal dan Hisam, 2018) bahwa peningkatan kinerja dan meningkatnya penghargaan yang diperoleh perusahaan disebabkan oleh kerjasama tim, kepercayaan kepemimpinan dan struktur organisasi.
Tabel 7. Penilaian SOTA komponen Infoware

\begin{tabular}{|c|c|c|}
\hline No & Kriteria Infoware & Skor \\
\hline 1 & $\begin{array}{llr}\text { Sistem } & \text { Informasi } & \text { Perusahaan } \\
\text { untuk } & \text { Mendukung } & \text { Aktivitas } \\
\text { Perusahaan } & \end{array}$ & 5 \\
\hline 2 & $\begin{array}{llr}\text { Informasi } & \text { Perusahaan } & \text { Secara } \\
\text { Publik } & & \\
\end{array}$ & 0 \\
\hline 3 & $\begin{array}{l}\text { Penyimpanan dan Pengambilan } \\
\text { Informasi Kembali }\end{array}$ & 4 \\
\hline & Total & 9 \\
\hline & Rata-rata & 3 \\
\hline
\end{tabular}

Sumber : Data primer, diolah (2021) 


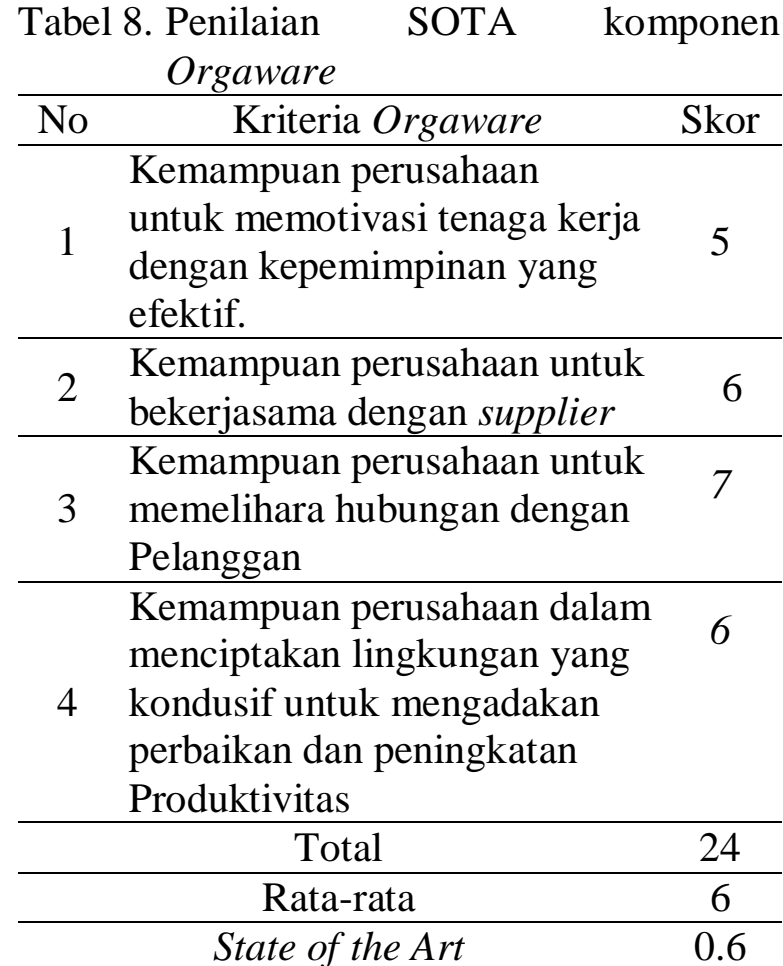

Sumber : Data primer, diolah (2021)

Nilai State of the Art komponen orgaware menunjukkan semua kriteria mempunyai nilai tinggi, kecuali kriteria nomor 1. Nilai State of the Art komponen infoware lebih kecil dari orgaware. Hal ini disebkan karena pemilik UKM masih belum memiliki pengetahuan mengenai pemanfaatan atau penggunaan teknologi informasi dalam proses produksi maupun penjualan produk keripik singkong. Hasil penelitian Subali (2019) menunjukkan bahwa ada dua negatif persepsi yang menyebabkan pelaku bisnis enggan mengadopsi teknologi informasi, yaitu: biaya investasi yang tinggi dan faktor budaya pekerja yang menyebabkan kesulitan dalam mencari informasi teknologi.

Hasil penghitungan state of the art (SOTA) menunjukkan bahwa tingkat kompleksitas tertinggi berada pada komponen teknologi orgaware sebesar 0.6. Tingginya nilai tersebut menunjukkan bahwa UKM sudah banyak memiliki jaringan untuk pemasaran produk maupun menjalin kerjasama dengan para supplier agar proses produksi terus berjalan lancar dan produk dapat terjual habis. Karena menjalin kemitraan dengan pelaku bisnis lainnya merupakan salah satu strategi untuk meminimasi terjadinya risiko atau menurunkan dampak yang disebabkan dari risiko pada proses produksi (Yahman et al, 2020).

\section{Kontribusi komponen teknologi}

Hasil penilaian Nilai kontribusi komponen teknologi pada UKM Gazal Makmur ditunjukkan pada Tabel 9.

Tabel 9. Nilai kontribusi komponen teknologi ukm gazal makmur

\begin{tabular}{lc}
\hline \multicolumn{1}{c}{ Komponen } & Nilai Kontribusi \\
\hline Technoware & 0.244 \\
Humanware & 0.467 \\
Infoware & 0.252 \\
Orgaware & 0.578 \\
\hline
\end{tabular}

Sumber : Data primer, diolah (2021)

Nilai kontribusi komponen teknologi disajikan pada Tabel 9, yang menunjukkan nilai kontribusi paling besar yaitu komponen orgaware, diikuti komponen humanware, infoware, dan yang terakhir technoware. Besarnya kontribusi orgaware ini cenderung dipengaruhi oleh nilai tepi bawah yang lebih tinggi (5) daripada nilai tepi bawah komponen lain. Adanya jaringan kerjasama dengan perusahaan lain dalam memasarkan produk menjadi kekuatan besar untuk memastikan produk dapat dipasarkan. Kepastian pasar menjadi salah satu faktor keberlangsungan perusahaan. Selain itu, nilai tepi atas yang tinggi (7) karena produk akhir perusahaan berupa keripik singkong merupakan produk yang spesial menjadi pusat perhatian pengelolaan oleh perusahaan (Mason, Friesl dan Ford, 2017).

Komponen teknologi UKM Gazal Makmur memiliki porsi kontribusi yang berbeda. Nilai kontribusi komponen teknologi yang terbesar terdapat pada komponen orgaware yaitu sebesar 0,578. Nilai kontribusi terkecil berada pada komponen technoware yaitu sebesar 0,244. Nilai kontribusi komponen humanware dan inforware masingmasing sebesar 0,467dan 0,252. Berdasarkan nilai-nilai tersebut dapat diketahui bahwa komponen orgaware memiliki kontribusi besar dalam menentukan tingkat teknologi UKM Gazal Makmur. 
Intensitas kontribusi komponen

Tingkat teknologi sebuah UKM ditentukan berdasarkan nilai TCC. Tingkat teknologi dapat dilihat pada Tabel 11. Nilai TCC dari UKM Gazal Makmur ditunjukkan pada Tabel 11.

Tabel 12 Hasil perhitungan nilai TCC UKM Gazal Makmur

\begin{tabular}{|c|c|c|c|c|c|}
\hline \multirow{2}{*}{ Komponen Teknologi } & \multicolumn{2}{|c|}{ Tingkat kecanggihan } & \multirow{2}{*}{ Kontribusi } & \multirow{2}{*}{ Intensitas } & \multirow[b]{2}{*}{ TCC } \\
\hline & $\mathrm{Ll}$ & Ul & & & \\
\hline Technoware & 1 & 4 & 0,244 & 0.129 & \multirow{4}{*}{0.418} \\
\hline Humanware & 2 & 7 & 0,467 & 0.303 & \\
\hline Infoware & 1 & 4 & 0,252 & 0.177 & \\
\hline Orgaware & 5 & 7 & 0,578 & 0.391 & \\
\hline
\end{tabular}

Sumber : Data primer, diolah (2021)

Hasil perhitungan menunjukkan UKM Gazal Makmur memiliki nilai TCC di bawah 0,7 dan di atas 0,3 sehingga dapat disimpulkan bahwa UKM ini tergolong memiliki level teknologi yang semi modern dengan klasifikasi TCC termasuk wajar untuk skala UKM.

\section{Koefisien kontribusi teknologi (TCC)}

Prioritas Pengembangan Komponen Teknologi Sebagai Upaya Peningkatan Mutu UKM Dalam technometric, intensitas kontribusi komponen (Intensity Of Importance) berfungsi untuk menentukan prioritas pengembangan ataupun peningkatan mutu, dimana pengembangan tersebut dimulai dengan prioritas pengembangan pada komponen teknologi yang mempunyai nilai intensitas kontribusi komponen tertinggi. Berdasar hasil penelitian ini, peningkatan mutu UKM keripik singkong Gazal Makmur dimulai dari komponen orgaware dimana UKM keripik singkong memiliki nilai kontribusi tertinggi pada komponen orgaware, kemudian humanware, infoware dan terakhir orgaware. Dengan kata lain peningkatan mutu dimulai dengan perbaikan organisasi, SDM, kemudian perbaikan data/informasi dan terakhir sarana prasarana. Gambar 1 merupakan gambar diagram THIO yang merupakan hasil penelitian ini.

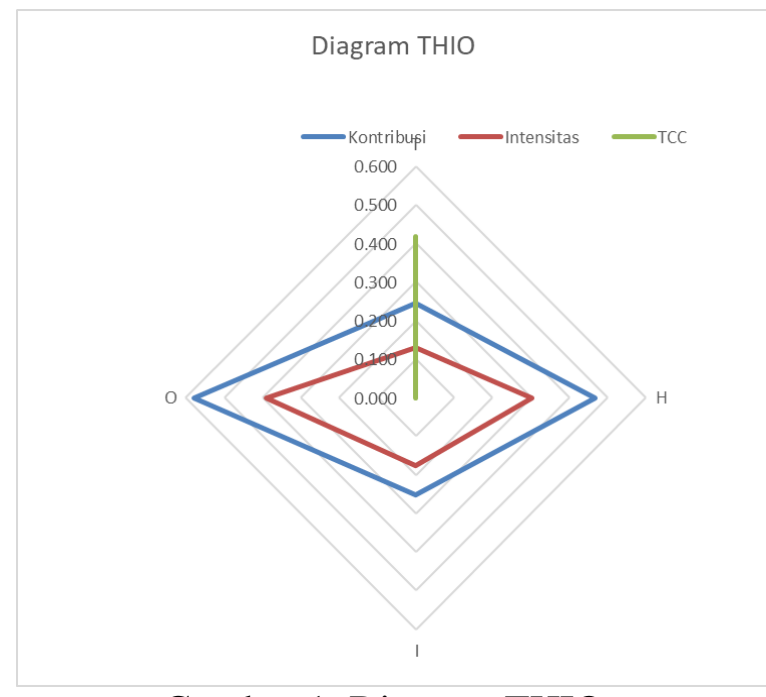

Gambar 1. Diagram THIO

\section{KESIMPULAN}

Dari Hasil Penelitian "Analisis Tingkat Kontribusi Teknologi Dalam Produksi Keripik singkong UKM Gazal Makmur Menggunakan Metode Technology Coefficient Contribution (TCC)" Ini dapat disimpulkan, kontribusi komponen Orgaware merupakan yang tertinggi pada UKM Gazal Makmur (0.578), kemudian humanware (0.467), humanware (0.252), dan yang terkecil technoware (0. 0.244). Nilai TCC untuk UKM Gazal Makmur ialah 0.418. Hasil perhitungan ini menunjukkan bahwa UKM ini memiliki nilai TCC dibawah 0,7 dan diatas 0,3 ,berarti dapat disimpulkan bahwa UKM ini yang berada di tergolong memiliki level teknologi yang semi modern dengan kategori teknologi wajar untuk skala UKM. Berdasar hasil penelitian ini, peningkatan mutu UKM keripik singkong 
Gazal Makmur dimulai dari komponen orgaware dimana UKM keripik singkong memiliki nilai kontribusi tertinggi pada komponen orgaware, kemudian humanware, infoware dan terakhir orgaware. Dengan kata lain peningkatan mutu dimulai dengan perbaikan organisasi, SDM, kemudian perbaikan data/informasi dan terakhir sarana prasarana.

\section{UCAPAN TERIMA KASIH}

Terimakasih disampaikan sebesarbesarnya kepada Universitas Nurul Jadid Probolinggo.

\section{DAFTAR PUSTAKA}

Antesty, S., \& Tontowi, A. E. (2020). Analisi kontribusi komponen teknologi umkm kota bontang menggunakan metode teknometrik. Jurnal Riset Teknologi Industri, 14(2), 230-240.

Antesty, S., Tontowi, A. E., \& Kusumawanto, A. (2020). Mapping the degree of technological capability in small and medium industry of automotive components. ASEAN Journal of Systems Engineering, 4(1), 13-19.

Ayu, R.A. (2018). Analisis kontribusi komponen teknologi dalam pengembangan pertanian padi konvensional menuju organik dan pengaruhnya terhadap produksi padi dan produksi, produktivitas dan pendapatan usaha tani di Kecamatan Sambirejo, Kabupaten Sragen. Universitas Pembangunan Nasional. Yogyakarta.

BPS Kabupaten Probolinggo. (2020). Produksi tanaman pangan.

Kementerian Koperasi, Kecil, Menengah Republik Indonesia. (2019). Sinergitas Pengembangan KUMKM melalui Penguatan Peran Antar Lembaga. Kementerian KUKM RI.

Matin, Y. A., \& Toloui, A. (2014). Measuring Technological Level and Capability of the Industries in East
Azerbaijan and Providing Proper Strategies for Improvement and Promotion of Technology. Advances in Environmental Biology 8(25), 408413.

Novia, C., Saiful, S., \& Utomo, D. (2021). Analisis SWOT peningkatan daya saing pada UKM keripik nangka di Kabupaten Malang. Teknologi Pangan: Media Informasi dan Komunikasi Ilmiah Teknologi Pertanian, 12(1), 6977.

Purnomo CA, Hadi Y. (2017). Pengukuran kinerja umkm menggunakan performance prism. Spektrum Industri $15(2)$,

121-136. https://doi.org/10.12928/si.v15i2.7550

Sanyal, S., \& Hisam, M. W. (2018). The impact of teamwork on work performance of employees: A study of faculty members in Dhofar University. IOSR Journal of Business and Management, 20(3), 15-22.

Subali, S. B. W.(2019) Business owners'perception of the information technology process adoption in medium scale manufacturing companies in Indonesia. International Journal of Mechanical Engineering and Technology (IJMET), 10(1), 18-29.

Sulistiyowati, W., \& Jakaria, R. B. (2018). Assessment of Technology Content Level With Integrated Technometrics and Analytical Hierarchy Process (AHP) Methods in small and medium enterprises. IOP Conference Series: Materials Science and Engineering. Annual Applied Science And Engineering Conference, 434(1), 1-10.

Suryana, D. (2012). Mengenal teknologi mulai dari pengenalan, sejarah, dan sampai teknologi sekarang. andi offset. Yogyakarta

Susihono, W. (2013). Penilaian teknologi untuk menentukan posisi industri pesaing.J@ti Undip: Jurnal Teknik Industri, 7(2), 131-138.

UNESCAP (1989). Technology Atlas Project. A Framework For Technology Based Development: 
Technology Content Assessment \& Technology Climate Assessment, Volume 2 \& 3. Indrawati SW. 2003.

Utomo, S., \& Setiastuti, N. (2019). Penerapan Metode Technometrik Untuk Penilaian Kapabilitas Teknologi Industri Galangan Kapal Dalam Menyongsong Era Industri 4.0. JSAKTI (Jurnal Sains Komputer Dan Informatika), 3(1), 100-110

Wiratmaja, I.W \& Ma'ruf, A. (2004). The Assesment of Technology in Supporting Industry Located at Tegal Industrial Park. Proceddings of Marine Transportation Engineering Seminar. Osaka University.Jepang.

Yahman, M. B., Widada, D., \& Profita, A. (2020). Analisis risiko dan penentuan strategi mitigasi pada proses produksi beras. MATRIK: Jurnal Manajemen dan Teknik Industri Produksi, 20(2), 67-78.

Smith, R., \& Sharif, N. (2007). Understanding and acquiring technology assets for global competition. Technovation, 27(11), 643-649.

Mason, K., Friesl, M., \& Ford, C. J. (2017). Managing to make markets: Marketization and the conceptualization work of strategic nets in the life science sector. Industrial Marketing Management, 67, 52-69. 